\title{
Suction Catheter Size: An Assessment and Comparison of 3 Different Calculation Methods
}

\author{
Christopher J Russian MEd RRT-NPS RPSGT RST, Joshua F Gonzales MHA RRT-NPS RRT-SDS, \\ and Nicholas R Henry MSC RRT-NPS AE-C
}

\begin{abstract}
BACKGROUND: Current American Association for Respiratory Care (AARC) clinical practice guidelines recommend a suction catheter to endotracheal tube ratio (SC/ETT) based on the external diameter of the SC and the internal diameter of the ETT. An SC/ETT ratio of $<50 \%$ is consistent with the current recommendation. We theorized that a more satisfactory assessment of SC/ETT ratio could be accomplished using volume or area formulas and expansion of diameter recommendations. Some respiratory care texts recommend an SC/ETT ratio that exceeds the clinical practice guideline standard. METHODS: We calculated the internal volume and cross-sectional area of various ETT sizes, the external volume and cross-sectional area of various SC sizes, and the SC/ETT ratios. We also measured negative pressures created by suction in a lung model, during multiple suction maneuvers. RESULTS: Volume and area calculations provide an alternative method for determining the SC/ETT ratio. A volume or area ratio of $50 \%$ corresponds to a diameter ratio of $70 \%$. Negative pressures during suctioning remain low at the new ratios, so a larger SC than current clinical practice guidelines still allows adequate air passage between the SC and ETT. CONCLUSIONS: Our results support an alternative SC/ETT ratio when pairing SCs and ETTs. Key words: suction catheter; endotracheal tube; endotracheal suctioning; airway clearance. [Respir Care 2014;59(1):32-38. (C) 2014 Daedalus Enterprises]
\end{abstract}

\section{Introduction}

In 1960 Rosen and Hillard published an extensive paper on the use of suctioning during clinical practice, and then a follow-up study in 1962 that focused specifically on negative pressure during tracheal suctioning. ${ }^{1,2}$ They introduced a formula to determine the negative pressure genThe authors are affiliated with the Department of Respiratory Care, Texas
State University, San Marcos, Texas.

Mr Russian presented a version of this paper at the OPEN Forum of the 2011 AARC Congress, held November 5-8, 2011, in Tampa, Florida.

This study was partly supported by a grant from Texas State University. The suction catheters were donated by Kimberly-Clark. Kimberly-Clark had no other involvement in the study. The authors have disclosed no conflicts of interest.

Correspondence: Christopher J Russian MEd RRT-NPS RPSGT RST, Department of Respiratory Care, Texas State University, 601 University Drive, San Marcos TX 78666. E-mail: cr23@txstate.edu.

DOI: $10.4187 /$ respcare. 02168 erated within the lungs during suctioning. Based on their calculations they recommended that the suction catheter (SC) should be no more than half the diameter of the endotracheal tube (ETT). Those were the seminal publications on SC/ETT ratios. Regardless of widespread acceptance of an SC/ETT ratio based on tube diameter, there is evidence that clinicians and researchers use larger ratios than recommended. ${ }^{3-6}$

The American Association for Respiratory Care (AARC) convened an expert panel to develop and periodically update clinical practice guidelines (CPG) on suctioning the artificial airway of the mechanically ventilated patient. ${ }^{7,8}$ Section 2.0 of the AARC endotracheal suctioning CPG suggests selecting an SC based on the internal diameter (ID) of the artificial airway. ${ }^{8}$ The expert panel cited 2 studies ${ }^{9,10}$ to support this recommendation. However, Tiffin et al suggested using an SC/ETT ratio based on tube crosssectional area, rather than diameter. ${ }^{9}$ Pedersen et al (a study not cited in the AARC CPG) suggested that "the suction catheter should occlude less than half the internal lumen, rather than half the diameter of the ET-tube."11 They considered lumen synonymous with volume, and 
provided a volume formula in their paper. ${ }^{11}$ Collectively; there exist 3 different options for determining the relationship between SC and ETT size: diameter, volume, and cross-sectional area.

We calculated the internal volumes and cross-sectional areas of multiple ETTs, calculated the external volumes and cross-sectional areas of multiple SCs, recorded the negative pressures generated during suctioning of an airway model, and compared the current AARC CPG recommendations with our calculated volumes, areas, and ratios.

\section{Methods}

This study was granted exemption status by the institutional review board at Texas State University-San Marcos. The study was performed in the instrumentation lab in the Department of Respiratory Care. We calculated the internal volumes and internal cross-sectional areas of various ETT sizes, the external volumes and external areas of various SC sizes, and the SC/ETT ratios. Standard geometry formulae for the volume and area calculations were used. We studied ETT sizes from 2.0 to $10.0 \mathrm{~mm}$ internal diameter (ID), and SC sizes from 4 to 16 French. The following millimeter and French conversions were used when necessary ${ }^{12}$ :

$$
\begin{aligned}
& 1 \mathrm{~mm}=3 \text { French } \\
& 0.33 \mathrm{~mm}=1 \text { French }
\end{aligned}
$$

Internal diameter and ETT length were used to calculate ETT volume. We relied on the manufacturer labels for the ETT IDs. The $15 \mathrm{~mm}$ ETT connector was not included in the measurements. ETT length was measured from the distal end of the ETT $15 \mathrm{~mm}$ connector, while inserted in the ETT, to the proximal end of the Murphy eye. External diameter and length were used to calculate SC external volume. Length is crucial to volume measurements, so SC and ETT length were matched for the calculations. Original ETT length per the manufacturer was not altered, thus the ETT length determined SC length and the resulting volumes. The SC external diameter was measured with a digital caliper. Volume calculations were converted from cubic millimeters to milliliters. We calculated the ratio of the external volume of the SC to the internal volume of the ETT (SC/ETT volume ratio) for all measured sizes. ETT ID and SC external diameter were used to calculate crosssectional area. We also calculated the ratio of the external area of the SC to the internal area of the ETT (SC/ETT area ratio) for all measured sizes.

We measured negative pressures during suctioning of an airway model consisting of corrugated and oxygen tubing. Cuffed ETTs ranging from 6 to $10 \mathrm{~mm}$ ID (SunMed, Largo, Florida) were inserted into corrugated tubing (di-

\section{QUICK LOOK}

\section{Current knowledge}

The current American Association for Respiratory Care clinical practice guidelines recommend choosing suction catheter size based on the external diameter of the suction catheter and the internal diameter of the endotracheal tube: a ratio of $<50 \%$ is recommended, to prevent suctioning-related complications, including hypoxemia.

\section{What this paper contributes to our knowledge}

A calculated suction-catheter-to-endotracheal-tube ratio of $50 \%$ of the endotracheal tube area or $50 \%$ of the endotracheal tube volume is equivalent to $<70 \%$ of the endotracheal tube diameter. A ratio of $<70 \%$ allows the clinician to determine the proper suction catheter size by doubling the endotracheal tube size. However, the appropriate suction catheter size should be judged by patient response to the procedure.

ameter $21.0 \mathrm{~mm}$, length $30 \mathrm{~cm}$ ). Cuffed ETTs of $4.0 \mathrm{~mm}$ and $5.0 \mathrm{~mm}$ ID (SunMed, Largo, Florida) were inserted into pediatric ventilator corrugated tubing (diameter $16.0 \mathrm{~mm}$, length $30 \mathrm{~cm}$ ). A cuffed ETT of $3.0 \mathrm{~mm}$ ID (Wai Medical, Viroqua, Wisconsin) was inserted into neonatal ventilator corrugated tubing (diameter $10.6 \mathrm{~mm}$, length $23 \mathrm{~cm}$ ). An uncuffed ETT of $2.0 \mathrm{~mm}$ ID (Sheridan/ Teleflex, Research Triangle Park, North Carolina) was inserted into oxygen tubing (diameter $4.0 \mathrm{~mm}$, length $19 \mathrm{~cm}$ ). Half-size ETTs (eg, $5.5 \mathrm{~mm}$ ID) were not used for this portion of the study.

A negative pressure manometer (Instrumentation Industries, Bethel Park, Pennsylvania) was connected to the distal end of each lung model and opposite the ETT point of insertion. The use of cuffed ETTs created a seal between the ETT and the airway model. This seal was crucial to our experiments, because it prevented air passage between the ETT and the airway model, thus reducing pressure attenuation from that pathway. Since the $2.0 \mathrm{~mm}$ ID ETT does not have a cuff, a 19-cm length of oxygen tubing was used as the airway model. Insertion of the ETT to the hub created a seal between the ETT and the oxygen tubing. Similar to the corrugated tubing models, a pressure manometer was attached to the distal end of the oxygen tubing, to measure lung pressure during suctioning. Pressures were recorded with the $2.0 \mathrm{~mm}$ ID ETT fully inserted into the oxygen tubing, to simulate a sealed ETT scenario.

In-line SCs (Kimberly-Clark, Roswell, Georgia) were connected to each ETT, with the suction line connected to a vacuum source. The vacuum source was adjusted to 
Table 1. Suction Pressures Applied

\begin{tabular}{lc}
\hline \hline $\begin{array}{c}\text { ETT ID } \\
\mathrm{mm}\end{array}$ & $\begin{array}{c}\text { Negative } \\
\text { Suction } \\
\text { Pressure } \\
(\mathrm{mm} \mathrm{Hg})\end{array}$ \\
\hline$\geq 6$ & 150 \\
5.0 & 120 \\
4.0 & 100 \\
3.0 & 100 \\
2.0 & 80 \\
\hline ETT = endotracheal tube & \\
ID $=$ internal diameter & \\
\hline
\end{tabular}

adhere to AARC CPG specifications, based on patient population (Table 1). ${ }^{8,13}$

Each SC was inserted into the ETT until it reached the tip of the ETT. Suction was applied as the catheter was slowly withdrawn. The maximum negative pressure generated was recorded. The suctioning procedure was repeated to achieve 2 identical negative pressures. If the negative pressures differed by more than $2 \mathrm{~cm} \mathrm{H}_{2} \mathrm{O}$, the procedure was repeated. The "ventilator connection" of the in-line SC remained open during all suctioning maneuvers, so air passage was possible between the SC and ETT, depending on the SC/ETT ratio.

\section{Results}

Table 2 displays the external volume calculations for the SCs. A 14 French SC was compared to several ETTs of different lengths, so $\mathrm{SC}$ volume for each length is reported. Table 3 displays the external area calculations for the SCs. Table 4 displays the internal volumes and internal areas calculations for the ETTs. Table 5 displays an SC size comparison based on the AARC endotracheal suctioning CPG and our area and volume calculations. Due to the current AARC CPG language Table 5 has a column for $<50 \%$ and a column for $\leq 50 \%$. The area and volume recommendations are based on 50\% of the ETT area and volume calculations, respectively. Our 50\% area and volume calculations match the $<70 \%$ diameter calculations. The SC sizes in Table 5 are limited to 14 French. A larger $\mathrm{SC}$ is possible with certain ETTs (eg, $10 \mathrm{~mm}$ ID). Table 6 displays the suctioning pressure results from our airway model. A curvilinear change in negative pressure occurs based on the SC/ETT ratio.

\section{Discussion}

Our calculations allow comparison of SC/ETT area and volume ratios with diameter ratios per the current AARC CPG. Selection of an SC that is $50 \%$ of the internal area or
Table 2. Suction Catheter External Diameters, Lengths, and External Volumes

\begin{tabular}{|c|c|c|c|}
\hline \multicolumn{2}{|c|}{ External Diameter } & \multirow{2}{*}{$\begin{array}{c}\text { Length } \\
(\mathrm{mm})\end{array}$} & \multirow{2}{*}{$\begin{array}{l}\text { Volume } \\
\text { (mL) }\end{array}$} \\
\hline French & $(\mathrm{mm})$ & & \\
\hline 16.0 & 5.3 & 302 & 6.7 \\
\hline 16.0 & 5.3 & 290 & 6.5 \\
\hline 16.0 & 5.3 & 280 & 6.3 \\
\hline 16.0 & 5.3 & 270 & 6.0 \\
\hline 14.0 & 4.7 & 302 & 5.2 \\
\hline 14.0 & 4.7 & 290 & 5.0 \\
\hline 14.0 & 4.7 & 280 & 4.8 \\
\hline 14.0 & 4.7 & 270 & 4.6 \\
\hline 14.0 & 4.7 & 260 & 4.4 \\
\hline 12.0 & 4.0 & 302 & 3.8 \\
\hline 12.0 & 4.0 & 290 & 3.6 \\
\hline 12.0 & 4.0 & 280 & 3.5 \\
\hline 12.0 & 4.0 & 270 & 3.4 \\
\hline 12.0 & 4.0 & 260 & 3.3 \\
\hline 12.0 & 4.0 & 230 & 2.9 \\
\hline 10.0 & 3.3 & 270 & 2.4 \\
\hline 10.0 & 3.3 & 260 & 2.3 \\
\hline 10.0 & 3.3 & 230 & 2.0 \\
\hline 8.0 & 2.7 & 280 & 1.6 \\
\hline 8.0 & 2.7 & 270 & 1.5 \\
\hline 8.0 & 2.7 & 260 & 1.5 \\
\hline 8.0 & 2.7 & 230 & 1.3 \\
\hline 7.0 & 2.3 & 230 & 1.0 \\
\hline 6.0 & 2.0 & 230 & 0.7 \\
\hline 5.0 & 1.7 & 230 & 0.5 \\
\hline 4.0 & 1.3 & 230 & 0.3 \\
\hline
\end{tabular}

Table 3. Suction Catheter Sizes and Calculated External Areas

\begin{tabular}{|c|c|c|}
\hline \multicolumn{2}{|c|}{ External Diameter } & \multirow{2}{*}{$\begin{array}{c}\text { Area } \\
\left(\mathrm{mm}^{2}\right)\end{array}$} \\
\hline French & $(\mathrm{mm})$ & \\
\hline 16 & 5.3 & 21.9 \\
\hline 14 & 4.7 & 16.8 \\
\hline 12 & 4.0 & 12.3 \\
\hline 10 & 3.3 & 8.5 \\
\hline 8 & 2.7 & 5.5 \\
\hline 7 & 2.3 & 4.2 \\
\hline 6 & 2.0 & 3.1 \\
\hline 5 & 1.7 & 2.1 \\
\hline 4 & 1.3 & 1.4 \\
\hline
\end{tabular}

$50 \%$ of the internal volume of an ETT equates to an SC that is $<70 \%$ of the diameter of an ETT. This relationship applies to adult, pediatric, and neonatal ETTs. Per the AARC CPG, only infants can be suctioned with an SC that is $<70 \%$ of the ETT diameter. The calculations for area and volume require somewhat complicated formulae, versus using diameter calculations. Equally, ETT diameter calculations require a conversion from millimeter to 


\section{Suction Catheter Size: An Assessment of 3 Different Calculation Methods}

Table 4. Endotracheal Tube Diameters, Lengths, Internal Volumes, Calculated Maximum Volume Displacements, Cross-Sectional Areas, and Maximum Areas of Encroachment

\begin{tabular}{|c|c|c|c|c|c|c|}
\hline $\begin{array}{c}\text { Internal } \\
\text { Diameter } \\
\mathrm{mm}\end{array}$ & $\begin{array}{l}\text { Internal } \\
\text { Diameter } \\
\text { French }\end{array}$ & $\begin{array}{l}\text { Length } \\
(\mathrm{mm})\end{array}$ & $\begin{array}{c}\text { Internal } \\
\text { Volume } \\
(\mathrm{mL})\end{array}$ & $\begin{array}{l}\text { Maximum Volume } \\
\text { Displacement } \\
\text { (50\% of calculated } \\
\text { volume) } \\
(\mathrm{mL})\end{array}$ & $\begin{array}{c}\text { Cross-Sectional } \\
\text { Area } \\
\left(\mathrm{mm}^{2}\right)\end{array}$ & $\begin{array}{l}\text { Maximum Area of } \\
\text { Encroachment } \\
\text { (50\% of calculated } \\
\text { area) } \\
\left(\mathrm{mm}^{2}\right)\end{array}$ \\
\hline 10.0 & 30.0 & 302 & 23.7 & 11.9 & 78.5 & 39.3 \\
\hline 9.5 & 28.5 & 302 & 21.4 & 10.7 & 70.8 & 35.4 \\
\hline 9.0 & 27.0 & 302 & 19.2 & 9.6 & 63.6 & 31.8 \\
\hline 8.5 & 25.5 & 302 & 17.1 & 8.6 & 56.7 & 28.4 \\
\hline 8.0 & 24.0 & 302 & 15.2 & 7.6 & 50.2 & 25.1 \\
\hline 7.5 & 22.5 & 302 & 13.3 & 6.7 & 44.2 & 22.1 \\
\hline 7.0 & 21.0 & 290 & 11.2 & 5.6 & 38.5 & 19.2 \\
\hline 6.5 & 19.5 & 280 & 9.3 & 4.6 & 33.2 & 16.6 \\
\hline 6.0 & 18.0 & 270 & 7.6 & 3.8 & 28.3 & 14.1 \\
\hline 5.5 & 16.5 & 260 & 6.2 & 3.1 & 23.7 & 11.9 \\
\hline 5.0 & 15.0 & 230 & 4.5 & 2.3 & 19.6 & 9.8 \\
\hline 4.5 & 13.5 & 230 & 3.7 & 1.8 & 15.9 & 7.9 \\
\hline 4.0 & 12.0 & 230 & 2.9 & 1.4 & 12.6 & 6.3 \\
\hline 3.5 & 10.5 & 230 & 2.2 & 1.1 & 9.6 & 4.8 \\
\hline 3.0 & 9.0 & 230 & 1.6 & 0.8 & 7.1 & 3.5 \\
\hline 2.5 & 7.5 & 230 & 1.1 & 0.6 & 4.9 & 2.5 \\
\hline 2.0 & 6.0 & 230 & 0.7 & 0.4 & 3.1 & 1.6 \\
\hline
\end{tabular}

Table 5. Suction Catheter Size Recommendations Based on American Association for Respiratory Care Clinical Practice Guideline ${ }^{2}$ and Area and Volume Calculations

\begin{tabular}{|c|c|c|c|c|c|c|}
\hline \multirow{3}{*}{$\begin{array}{c}\text { ETT } \\
\text { Internal } \\
\text { Diameter } \\
\text { mm }\end{array}$} & \multicolumn{6}{|c|}{ Suction Catheter Size, French } \\
\hline & \multicolumn{4}{|c|}{ Based on American Association for Respiratory Care Clinical Practice Guideline } & \multirow{2}{*}{$\begin{array}{c}\begin{array}{c}\text { Based on Area } \\
\text { Calculation }\end{array} \\
\leq 50 \% \text { of ETT } \\
\text { Area Calculation }\end{array}$} & \multirow{2}{*}{$\begin{array}{c}\begin{array}{c}\text { Based on Volume } \\
\text { Calculation }\end{array} \\
\leq 50 \% \text { of ETT } \\
\text { Volume Calculation }\end{array}$} \\
\hline & $\begin{array}{l}<50 \% \text { of the ETT } \\
\text { Internal Diameter }\end{array}$ & $\begin{array}{l}\leq 50 \% \text { of the ETT } \\
\text { Internal Diameter }\end{array}$ & $\begin{array}{l}\leq 66 \% \text { of the ETT } \\
\text { Internal Diameter }\end{array}$ & $\begin{array}{l}<70 \% \text { of the ETT } \\
\text { Internal Diameter }\end{array}$ & & \\
\hline 10.0 & 14 & 14 & $14 *$ & $14^{*}$ & $14^{*}$ & $14^{*}$ \\
\hline 9.5 & 14 & 14 & $14^{*}$ & $14^{*}$ & $14^{*}$ & $14^{*}$ \\
\hline 9.0 & 12 & 12 & $14^{*}$ & $14^{*}$ & $14^{*}$ & $14^{*}$ \\
\hline 8.5 & 12 & 12 & $14^{*}$ & $14^{*}$ & $14^{*}$ & $14^{*}$ \\
\hline 8.0 & 10 & 12 & 14 & $14^{*}$ & $14^{*}$ & $14^{*}$ \\
\hline 7.5 & 10 & 10 & 14 & 14 & 14 & 14 \\
\hline 7.0 & 10 & 10 & 12 & 14 & 14 & 14 \\
\hline 6.5 & 8 & 8 & 12 & 12 & 12 & 12 \\
\hline 6.0 & 8 & 8 & 10 & 12 & 12 & 12 \\
\hline 5.5 & 8 & 8 & 10 & 10 & 10 & 10 \\
\hline 5.0 & 7 & 7 & 8 & 10 & 10 & 10 \\
\hline 4.5 & 6 & 6 & 8 & 8 & 8 & 8 \\
\hline 4.0 & 5 & 6 & 7 & 8 & 8 & 8 \\
\hline 3.5 & 5 & 5 & 6 & 7 & 7 & 7 \\
\hline 3.0 & 4 & 4 & 5 & 6 & 6 & 6 \\
\hline 2.5 & 2 & 2 & 5 & 5 & 5 & 5 \\
\hline 2.0 & 2 & 2 & 4 & 4 & 4 & 4 \\
\hline
\end{tabular}

French, to match SC sizing. However, there is a quick method available to determine the SC/ETT ratio. Choosing an SC that is $<70 \%$ of the ETT ID only requires that the clinician double the millimeter diameter size of the ETT to 
Suction Catheter Size: An Assessment of 3 Different Calculation Methods

Table 6. Achieved Suction Pressure Versus ETT Internal Diameter, Suction Catheter Size, and Set Suction Pressure

\begin{tabular}{|c|c|c|c|c|c|c|c|c|c|}
\hline \multirow{3}{*}{$\begin{array}{l}\text { ETT } \\
\text { Internal } \\
\text { Diameter } \\
\text { mm }\end{array}$} & \multicolumn{8}{|c|}{ Negative Pressure Achieved, $\mathrm{cm} \mathrm{H}_{2} \mathrm{O}$} & \multirow{3}{*}{$\begin{array}{c}\text { Set } \\
\text { Negative } \\
\text { Suction } \\
\text { Pressure } \\
(\mathrm{mm} \mathrm{Hg})\end{array}$} \\
\hline & \multicolumn{8}{|c|}{ Suction Catheter Size, French } & \\
\hline & 16 & 14 & 12 & 10 & 8 & 7 & 6 & 5 & \\
\hline $10.0^{*}$ & 2 & 1 & & & & & & & 150 \\
\hline 9.5 & 4 & 3 & & & & & & & 150 \\
\hline 9.0 & 4 & 3 & 1 & & & & & & 150 \\
\hline 8.5 & 8 & 4 & 1 & & & & & & 150 \\
\hline 8.0 & 13 & 6 & 2 & & & & & & 150 \\
\hline 7.5 & 28 & 10 & 3 & 1 & & & & & 150 \\
\hline 7.0 & 40 & 13 & 4 & 1 & & & & & 150 \\
\hline 6.5 & 98 & 22 & 4 & 1 & & & & & 150 \\
\hline 6.0 & 120 & 52 & 12 & 4 & 1 & & & & 150 \\
\hline $5.0 \dagger$ & DNF & 88 & 40 & 10 & 4 & 1 & & & 120 \\
\hline $4.0 \dagger$ & & DNF & DNF & 88 & 20 & 14 & 2 & & 100 \\
\hline $3.0 \ddagger$ & & & & DNF & 120 & 78 & 18 & 4 & 100 \\
\hline $2.0 \S$ & & & & & DNF & DNF & DNF & 100 & 80 \\
\hline \multicolumn{10}{|c|}{$\begin{array}{l}\text { * With the endotracheal tubes (ETTs) of } 6 \text { to } 10 \mathrm{~mm} \text { internal diamete } \\
\dagger \text { Pediatric ventilator circuit tubing was used for the airway model. } \\
\text { ₹eonatal ventilator circuit tubing was used for the airway model. } \\
\text { O Oxygen tubing was used for the airway model. } \\
\text { DNF = suction catheter does not fit into ETT }\end{array}$} \\
\hline
\end{tabular}

get the size of the SC in French. For example, a $7.0 \mathrm{~mm}$ ETT and a $7.5 \mathrm{~mm}$ ETT can accept a 14 French SC. This method to determine SC size applies for adult, pediatric, and neonatal ETTs. Furthermore, using an SC/ETT ratio exceeding the current AARC CPG recommendation is supported by 2 nationally recognized respiratory care textbooks. ${ }^{14,15}$ Table 5 demonstrates the comparison between the 3 methods.

It has been demonstrated that SCs that occlude half the area of the ETT do allow air to pass into the lungs during suctioning. ${ }^{9}$ Figure 1 illustrates a comparison of an $\mathrm{SC} /$ ETT ratio of $50 \%$ of the diameter versus $70 \%$ of the diameter. An SC that blocks 70\% of the ETT ID still allows half of the ETT internal area for air passage, which is crucial for minimizing the negative pressure generated within the lungs and allowing ambient air to enter the SC. Our airway model experiment allowed the generation of negative pressure during suctioning, and, as expected, the pressure applied to the model lung became more negative as the SC/ETT ratio increased (Fig. 2). High suction pressure did not appear to occur until beyond the $70 \%$ SC/ETT ratio.

Previous authors have calculated the negative pressure within the lungs when factoring in the applied suction pressure, the SC/ETT ratio, and the SC-ID/SC-externaldiameter ratio. ${ }^{1,2}$ As Figure 3 demonstrates, an SC/ETT diameter ratio of $50 \%$ appears to generate a negative pressure on the flat or less steep portion of all 3 curves. Depending on the SC characteristics, the steep portion of the
A

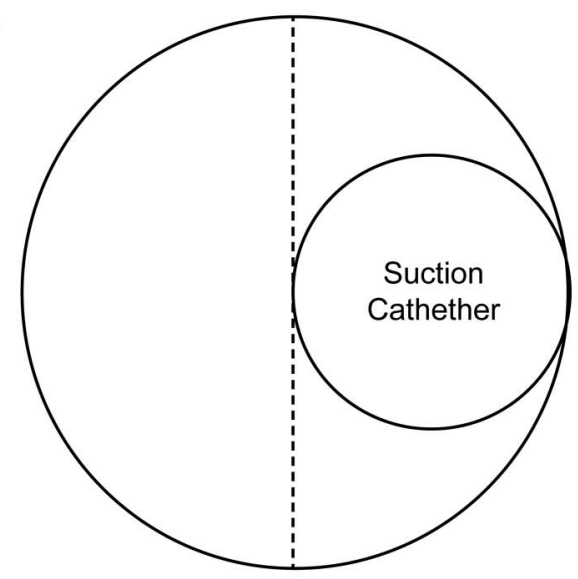

B

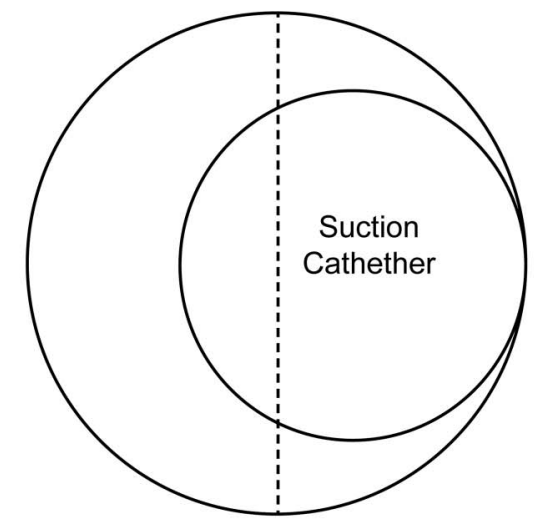

Fig. 1. Ratio of suction catheter outer diameter to endotracheal tube inner diameter. A: 50\%. B: $70 \%$. 


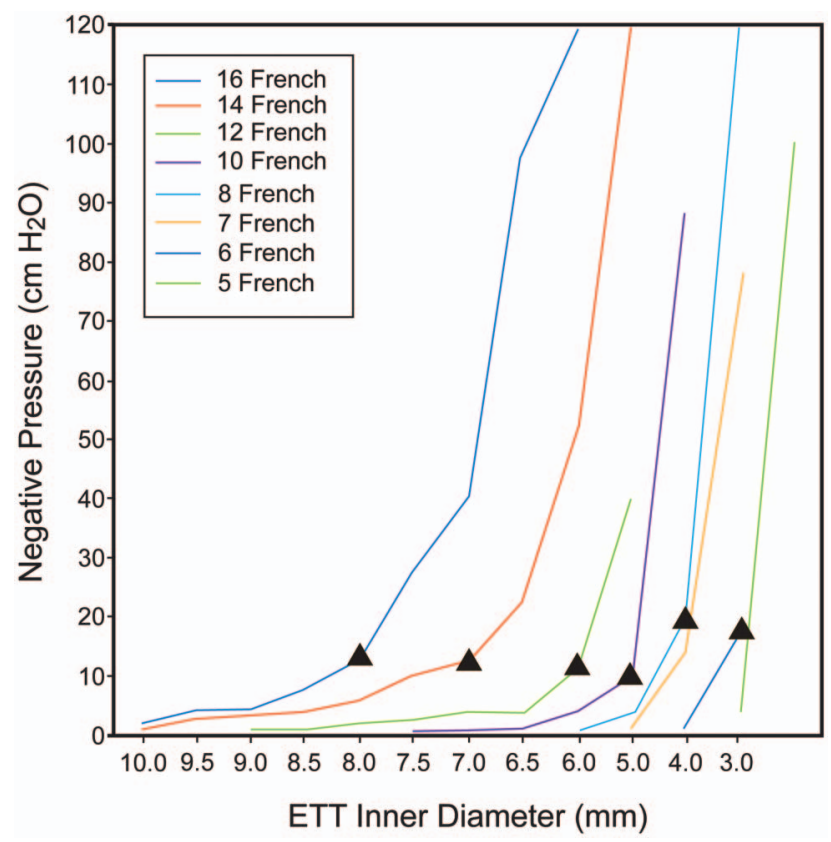

Fig. 2. Negative pressures generated in our airway model. The triangles indicate the recommended ratio of suction catheter outer diameter to endotracheal tube inner diameter, based on an area/ volume ratio of $50 \%$ and a diameter ratio of $70 \%$. Since we did not study endotracheal tube (ETT) half-sizes (eg, $6.5 \mathrm{~mm}$ ), we make no recommendation regarding the 7 French and 5 French suction catheters.

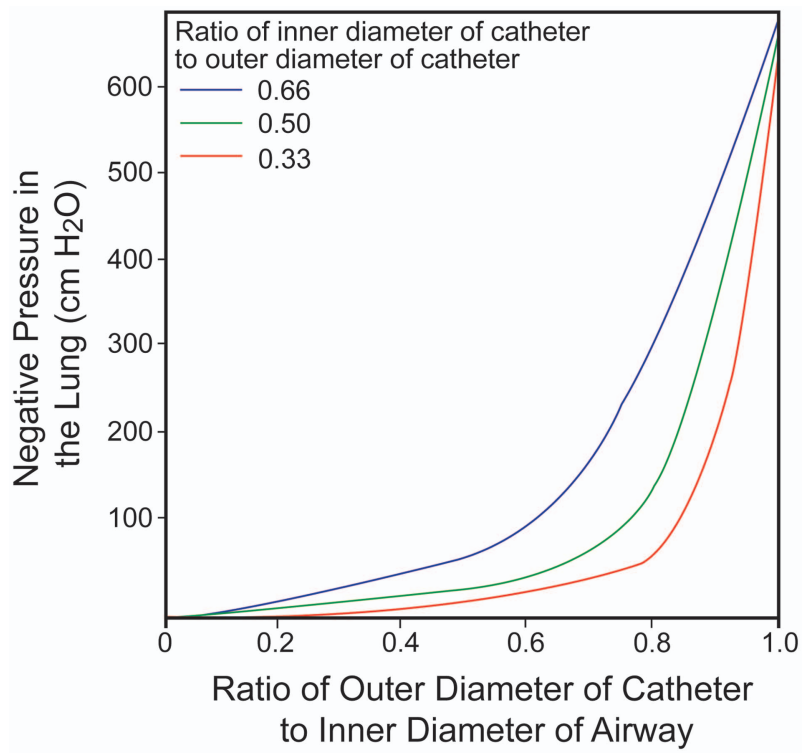

Fig. 3. Calculated negative pressure developed in the lung plotted against the outside diameter of the suction catheter to the inside diameter of the airway. Each curve represents a catheter with a different wall thickness, expressed as the ratio of the catheter's inner diameter to outer diameter. (Data from reference 1.)

curve does not occur until beyond an SC/ETT diameter ratio of $70 \%$ and suction pressure of $-200 \mathrm{~cm} \mathrm{H}_{2} \mathrm{O}$. In

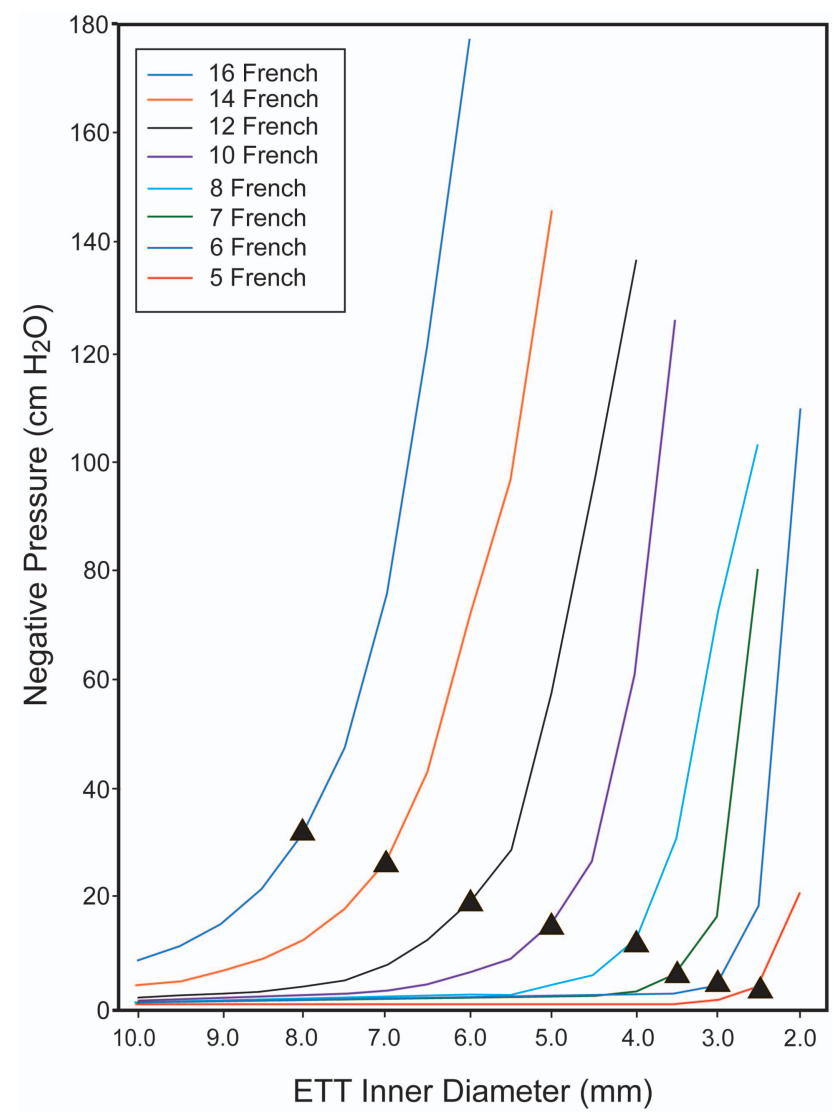

Fig. 4. Negative pressures calculated with the Rosen and Hillard formula. ${ }^{1,2}$ The triangles indicate the recommendations based on an area/volume ratio of $50 \%$ and a diameter ratio of $70 \%$. The American Association for Respiratory Care clinical practice guidelines suction pressures were converted to $\mathrm{cm} \mathrm{H}_{2} \mathrm{O}$ and used in the calculations.

addition, the suction pressure included in the original calculations (ie, $-500 \mathrm{~mm} \mathrm{Hg}$ ) is beyond the negative pressure recommended in the AARC CPG (ie, in adults $<-150 \mathrm{~mm} \mathrm{Hg})^{8}{ }^{8,13}$ The formula developed by those authors was used to recalculate and plot the relationship between suction pressure, SC size, and ETT size..$^{1,2}$ Suction pressures were based on the current AARC CPG. Figure 4 demonstrates the curvilinear relationship between the SC and ETT sizes. The black triangles indicate the recommended SC and ETT combinations based on a volume/area ratio of $50 \%$ and a diameter ratio of $<70 \%$. As the SC/ETT ratio exceeds $70 \%$, the calculated negative pressures approach the set suction pressure. The same curvilinear relationship was demonstrated with the airway model experiment.

\section{Limitations}

We did not assess the impact of a larger SC/ETT ratio on lung volumes. However, there is literature to address 


\section{Suction Catheter Size: An Assessment of 3 Different Calculation Methods}

this topic. ${ }^{16-18}$ Additional research to determine the changes in lung volume during suctioning with various SC sizes is warranted. SC size was limited to 14 French, despite results indicating that a larger SC is possible. The reasons were that we found no literature supporting the use of a 16 French SC with an adult ETT, and there is literature suggesting that a 14 French $\mathrm{SC}$ is acceptable for adult patients. ${ }^{14}$

Pulmonary secretions on the ETT wall decrease the ETT internal volume and cross-sectional area, and limit air passage during suctioning, which may increase the negative pressure within the lungs. We did not study the impact of secretions on ETT internal size and negative pressure.

We also did not study distal negative pressure with a completely closed suctioning set-up. The proximal end of the in-line SC remained open to the atmosphere. The proximal end of the in-line SC is a source for air passage during suctioning. Adding positive-pressure ventilation to the proximal end of the in-line SC would impact the negative pressure generated during suctioning.

Cuffed ETTs are not commonly used in neonatal and some pediatric patients. Without a cuff there is probably a leak between the ETT and the trachea, which would increase air passage during suctioning. We used cuffed ETTs to determine the negative pressure due to the SC/ETT ratio, so our suctioning results do not reflect clinical results that would occur with uncuffed ETTs.

\section{Conclusions}

A calculated SC/ETT ratio based on $50 \%$ of ETT area or $50 \%$ of ETT volume is equivalent to $<70 \%$ of the ETT diameter. Using a diameter ratio of $<70 \%$ would allow the clinician to quickly determine the proper SC size, by doubling the ETT size. This method for determining the $\mathrm{SC}$ ETT ratio allows for a larger $\mathrm{SC}$ than is recommended by the current AARC CPG. ${ }^{8}$ We stress, however, that our results establish the maximum $\mathrm{SC}$ size for each ETT. Bedside practitioners can select an SC that is smaller than the ratios provided above if the recommended size is unavailable or deemed inappropriate due to clinical outcomes.

\section{REFERENCES}

1. Rosen M, Hillard EK. The use of suction in clinical medicine. Brit J Anaesth 1960;32(10):486-504.
2. Rosen M, Hillard EK. The effects of negative pressure during tracheal suction. Anesth Analg 1962;41(1):50-57.

3. Witmer MT, Hess DR, Simmons M. An evaluation of the effectiveness of secretion removal with the ballard-circuit suction catheter. Respir Care 1991;36(8):844-848.

4. Fernández MD, Piacentini E, Blanch L, Fernández R. Changes in lung volume with three systems of endotracheal suctioning with and without pre-oxygenation in patients with mild-to-moderate lung failure. Intensive Care Med 2004;30(12):2210-2215. DOI: 10.1007/s00134004-2458-3.

5. Frengley RW, Closey DN, Sleigh JW, Torrance JM. The effect of closed system suction on airway pressures when using the Servo 300 ventilator. Crit Care Resuscitation 2001;3(4):230-235.

6. Day T, Wainwright S, Wilson-Barnett J. An evaluation of a teaching intervention to improve the practice of endotracheal suctioning in intensive care units. J Clin Nurs 2001;10(5):682-696.

7. American Association for Respiratory Care. AARC clinical practice guideline. Endotracheal suctioning of mechanically ventilated adults and children with artificial airways. Respir Care 1993;38(5):500-504.

8. American Association for Respiratory Care. AARC clinical practice guideline. Endotracheal suctioning of mechanically ventilated patients with artificial airways: 2010. Respir Care 2010;55(6):758-764.

9. Tiffin NH, Keim MR, Frewen TC. The effects of variations in flow through an insufflating catheter and endotracheal tube and suction catheter size on test lung pressures. Respir Care 1990;35(9):889-897.

10. Vanner NH, Bick E. Tracheal pressures during open suctioning. Anaesthesia 2008;63(3):313-315. DOI: 10.1111/j. 1365-2044.2007. 05348.

11. Pederson CM, Rosendahl-Nielsen M, Hjermind J, Egerod I. Endotracheal suctioning of the adult intubated patient-what is the evidence? Intensive Crit Care Nurs 2009;25(1):21-30. DOI: 10.1016/j. iccn.2008.05.004

12. Iserson KV. J.F.B. Charriére: the man behind the "French" gauge. J Emerg Med 1987;5(6):545-548.

13. American Association for Respiratory Care. AARC clinical practice guideline. Nasotracheal suctioning: 2004 revision and update. Respir Care 2004;49(9):1080-1084.

14. Davies JD, May RA, Bortner PL. Airway management. In: Hess, DR, MacIntyre NR, Mishoe SC, Galvin WF, Adams AB, editors. Respiratory care: principles and practice, 2nd edition. Sudbury, MA: Jones \& Bartlett Learning; 2012:376-418.

15. Altobelli N. Airway management. In: Kacmarek RM, Stoller JK, Heuer AJ, editors. Egan's fundamentals of respiratory care, 10th editon. St Louis: Elsevier; 2013:732-786.

16. Lindgren S, Almgren B, Hogman M, Lethvall S, Houltz E, Lundin S, Stenqvist O. Effectiveness and side effects of closed and open suctioning: an experimental evaluation. Intensive Care Med 2004;30(8): 1630-1637.

17. Morrow BM, Futter MJ, Argent AC. Endotracheal suctioning: from principles to practice. Intensive Care Med 2004;30(6):1167-1174. DOI: 10.1007/s00134-004-2238-0.

18. Tingay DG, Copnell B, Grant CA, Dargaville PA, Dunster KR, Schibler A. The effect of endotracheal suction on regional tidal ventilation and end-expiratory lung volume. Inten Care Med 2010; 36(5):888-896. DOI: 10.1007/s00134-010-1849-x.

This article is approved for Continuing Respiratory Care Education credit. For information and to obtain your CRCE

(free to AARC members) visit www.rcjournal.com

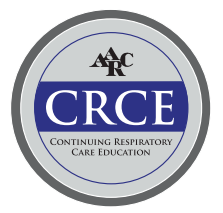

